\title{
pH Effect on Phosphorus Removal in Synthetic Wastewater by Using Electric Arc Furnace Lab-scale Filter
}

\author{
Syahrul Nizam Bin Maarup ${ }^{1, \text { a }}$, Palanisamy A/L Paramasivan 2,b \\ and Rafidah Binti Hamdan ${ }^{3, c}$
}

\author{
${ }^{1,2}$ Department of Water and Environmental Engineering, Faculty of Civil and Environmental \\ Engineering, Universiti Tun Hussein Onn Malaysia, Parit Raja, 86400 Batu Pahat, Johor, Malaysia, \\ ${ }^{3}$ Department of Civil Engineering Technology, Faculty of Engineering Technology, Universiti Tun \\ Hussein Onn Malaysia, Parit Raja, 86400 Batu Pahat, Johor, Malaysia \\ asyahrultse@gmail.com, 'saamy_52@yahoo.com, 'rafidahh@uthm.edu.my
}

Keywords: Aerated steel slag filter, eutrophication, lab-scale, phosphorus removal, synthetic wastewater.

\begin{abstract}
Phosphorus is known as non-renewable source and due to its high levels of phosphorus in water body may lead to eutrophication problems. It may come from many sources such as industry, agriculture and from wastewater treatment plant. Large excessive of phosphorus may increase the purification cost and serious water quality problem because of the effect of algae toxin in water. Conventional wastewater treatment plant (WWTP) requires lot of cost such as labour, capital and maintenance costs. Therefore, the lab-scale aerated steel slag filter (ASSF) emerged as an alternative method to remove phosphorus from water due to its simple and also low cost technology has been developed to overcome this problem. This lab-scale filter has been conducted by using synthetic wastewater for an eight weeks starting from 19 March until $4^{\text {th }}$ May 2014. This study is to investigate the effect of $\mathrm{pH}$ range from 4.5 to 7.5 and temperature for phosphorus removal mechanism. From this study, result shows that lab-scale ASSF achieve about $90 \%$ of phosphorus removal at $\mathrm{pH}$ 5.0. Based on X-ray fluorescence (XRF) analysis, the steel slag is rich in $\mathrm{Ca}, \mathrm{Al}$ and $\mathrm{Fe}$ which is enhance the $\mathrm{P}$ removal with the influence of $\mathrm{pH}$ for precipitation mechanism process in this experiment.
\end{abstract}

\section{Introduction}

Phosphorus that enters into the water body will cause an eutrophication problem to the water ecosystem. The wastewater contains phosphorus will raise the growth of algae in the water body. These algae used lots of oxygen and also will close water surface; hence will prevent the sunlight entering the water. This environment is fairly unlivable for other organisms. Excessive of phosphorus in wastewater is the main cause of eutrophication, otherwise it is normal if there is no excessive phosphorus in water although it critically needed by aquatic plant to live [1].

The main effect caused by eutrophication is species diversity will decrease, increase the water plant to growth, high in turbidity and high sedimentation rate. The changes in nutrient level and biology in water can affect human activities, can injurious to human health, increased vegetation in water body, important species of fish will decrease and difficult to treat drinking water. According to Valero [2], it requires about $75-80 \%$ removal in large wastewater treatment plants (WWTP) which is discharged into sensitive water. It may become eutrophic if protective action is not taken.

Nutrient removal using conventional method required a large amount of investment. Natural wastewater treatment is one of the low cost treatments which are combining of waste stabilization ponds and rock filters. Natural wastewater treatment is the wieldy use in European countries. Advantages of this natural wastewater treatment are low cost and easy to maintain. Rock filter known as the filter of submerged rock beds through the lagoon effluent flows or in the created filter. 
The rock media is about $5-20 \mathrm{~cm}$ rock with void space about $40-45 \%$ of the total volume. Rock filter mechanism is through the sedimentation, flotation, interception, adsorption and precipitation by media [3]. Un-aerated RF has been used more than three decades in the US and primarily in removing algal solid and biochemical oxygen demand (BOD) [4].

Slag is a material that produced in iron and steel production. Electric arc furnace slag is produced during the manufacture of crude steel by the electric arc furnace (EAF) process. In this process steel scrap with additions of fluxes are heated to a liquid state by means of an electric current. According to Bird [5], the phosphorus removal efficiency is about $>95 \%$ based on the vertical column fed with synthetic $\mathrm{P}$ solution. The EAF process is also a lower cost method than other technique because of energy efficiency of the process and smaller investment in the startup.

The HLR for this study, we suggested using $0.02 \mathrm{~m}^{3} / \mathrm{m}^{3}$.day this rate is considerate by the research done by (Swanson and Williamson, 1980) cited in [4]. The best rate less than $0.3 \mathrm{~m}^{3} / \mathrm{m}^{3}$.day will give the best performance as reported by Johnson et al., [6].

According to Zhang et al.,[7], $\mathrm{pH}$, chemical composition, duration, contact time and temperature are the most important factor for adsorption process but the more important mechanism is $\mathrm{pH}$. The $\mathrm{pH}$ value below 6 is a dominant chemical precipitation while above 8 is adsorption. Adsorption of phosphate ion is effective to adsorb phosphate ion at a $\mathrm{pH}$ of 5-8 as mentioned by [4] while [8] stated that adsorption occur at $\mathrm{pH} 6.0-8.0$. Adsorption efficiency has a great impact on substrates by chemical composition and the adsorbent usually contain alumina, iron, magnesium and calcium oxide, which is can contribute to phosphorus removal by using precipitation and adsorption processes. According to [9], total phosphate adsorption is highest in acidic conditions, but $50 \%$ of total available phosphorus can still be adsorbed to iron above $\mathrm{pH} 10$. It also depends on the binding capacity on $\mathrm{pH}$ for iron oxide and phosphate species.

\section{Material and Methods}

Lab scale vertical rock filter was installed in FKAAS Environmental Laboratory, UTHM. The lab scale filter schematic diagram is shown in Fig. 1 while lab scale filters in Fig. 2. Rock filter is designed to receive influent by gravity method. The filter has been built by using the Perspex pipe diameter $150 \mathrm{~mm}$ with $6 \mathrm{~mm}$ thickness and steel slag as filter media.

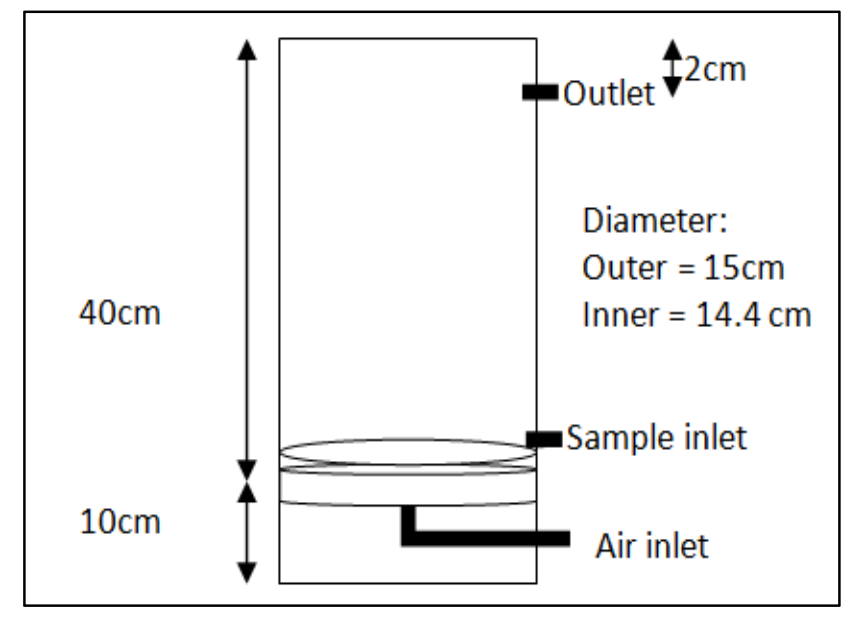

Fig. 1: Schematic Diagram of a Lab-scale Vertical Rock Filter

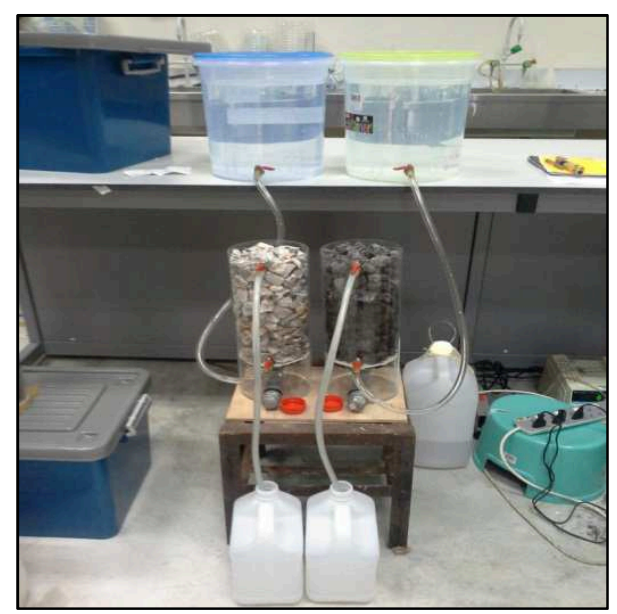

Fig. 2: Lab-scale Filter

Synthetic wastewater with initial concentration of $25 \mathrm{mg} \mathrm{P} / \mathrm{L}$ has been prepared by diluting a standard phosphate solution $(1000 \mathrm{mg} / \mathrm{L})$ with Deionized (DI) water. The $\mathrm{pH}$ of synthetic wastewater has been adjusted to 6.7 - 6.8 using a diluted $\mathrm{HCl}$. The synthetic wastewater before and after treating in rock filter has been analyzed with the two selected parameters. The method of analysis is shown in Table 1. 
Table 1: Wastewater Sample Analysis Method.

\begin{tabular}{|l|l|l|}
\hline Determination & Method of analysis & Frequency \\
\hline $\mathrm{pH}$, Temperature & YSI meter & Twice a week \\
\hline Total Phosphorus & $\begin{array}{l}\text { Discrete analyzer (Smartchem) } \\
\text { (Persulfate Digestion Method, 4500 P B) }\end{array}$ & \\
\hline
\end{tabular}

\section{Result and Discussion}

The different $\mathrm{pH}$ of wastewater will produce different mechanism in un-aerated rock filter. The data obtained from the tests that has been run for the past 2 months and has been collected from rock filter effluent, which is started from $19^{\text {th }}$ March 2014 until $4^{\text {th }}$ May 2014. The total of sample have collected is seven samples which are used to monitor parameters such as total phosphorus, $\mathrm{pH}$, temperature and removal efficiency. Table 2 below shows the result of the lab-scale testing.

Table 2: Lab-scale Filter Result

\begin{tabular}{|c|c|c|c|}
\hline Sampling & Parameter & $\begin{array}{c}\text { Removal } \\
\text { efficiency (\%) }\end{array}$ & $\begin{array}{c}\text { Final effluent } \\
\text { concentration } \pm \text { s.d }\end{array}$ \\
\hline 1 & Total Phosphorus & 89.6 & $13.4 \pm 5.11$ \\
\hline 2 & Temperature & - & $27.08 \pm 0.71$ \\
\hline
\end{tabular}

\section{Phosphorus Removal}

From Fig. 3, the highest removal of phosphorus is around $89.6 \%$ at the $\mathrm{pH}$ 5. This finding is comparable with the previous work which has found that chemical precipitation took place at $\mathrm{pH}$ 5.0 due to high solubility of $\mathrm{Ca}^{2+}$ from steel slag and this condition will enhance phosphate precipitation to become $\mathrm{CaPO}_{4}$ [9]. Influent concentration was maintained at $25 \mathrm{mg} / \mathrm{L}$ to cover the typical concentration of phosphorus in real wastewater.

Meanwhile, the lowest removal of $27.84 \%$ was occurred at $\mathrm{pH} 7$. This is because of the removal efficiency is not influenced to the $\mathrm{pH}$ changes due to unstable removal, however, it is also has been manipulated by other elements.
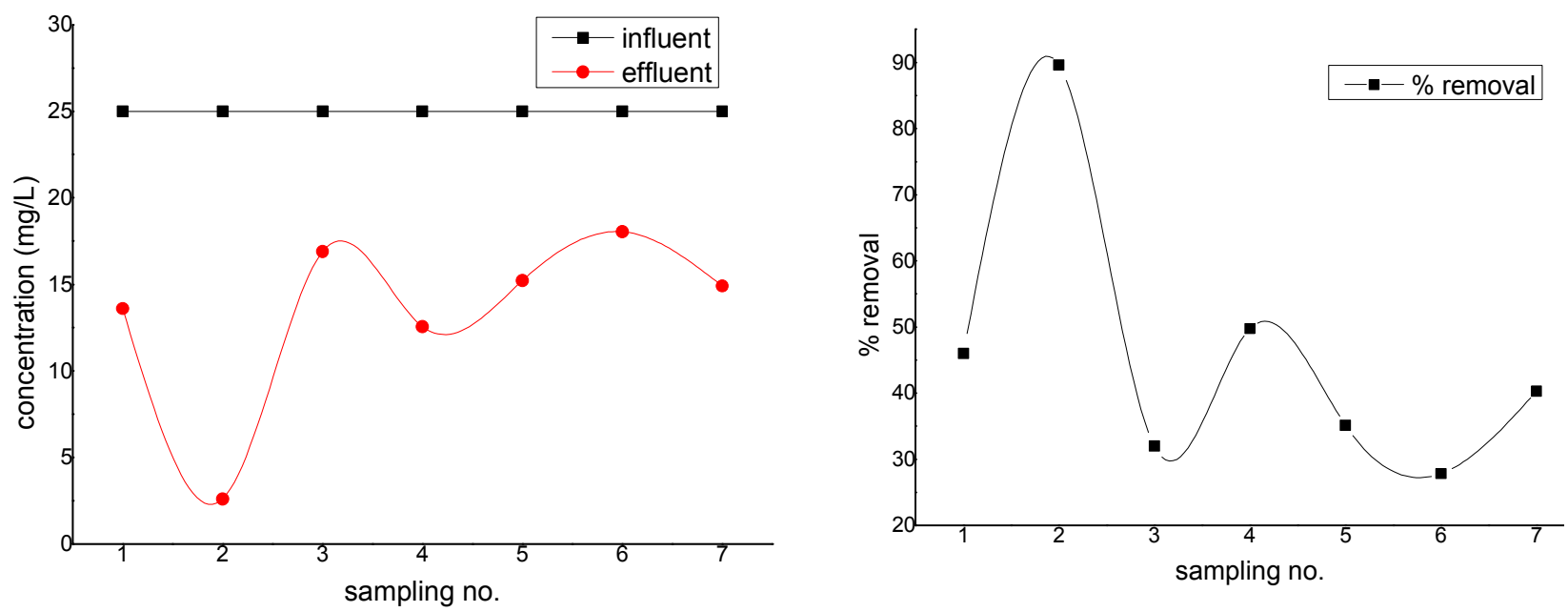

Fig. 3: Concentration vs Removal efficiency (\%)

$\mathrm{pH}$ is one of the environmental factors that affect the removal mechanism of phosphorus within the system. To study the effect of $\mathrm{pH}$ towards the removal of phosphorus in this experiment, the $\mathrm{pH}$ of synthetic wastewater has been adjusted from 4.5 to 7.5. The main concern in this experiment is the $\mathrm{pH}$ must be within typical of wastewater around from 5.5 to 8 . The result of $\mathrm{pH}$ showed in Fig. 4. The $\mathrm{pH}$ of solution plays a critical role in the rate and mechanism of phosphate removal. 
Phosphate removal probably is due to ion exchange between phosphate hydrolysis product $\left(\mathrm{H}_{2} \mathrm{PO}_{4}^{-} \mathrm{HPO}_{4}^{2-}\right)$ and the precipitations of the metallic salts of phosphate $\left(\mathrm{Al}^{3+}, \mathrm{Ca}^{2+}, \mathrm{Fe}^{3+}\right)$. The precipitation occurs in the experiment when the $\mathrm{pH}$ reaches 5.0 to 6.0 , Fig. 5 shows the precipitations of phosphate occur in the experiments.

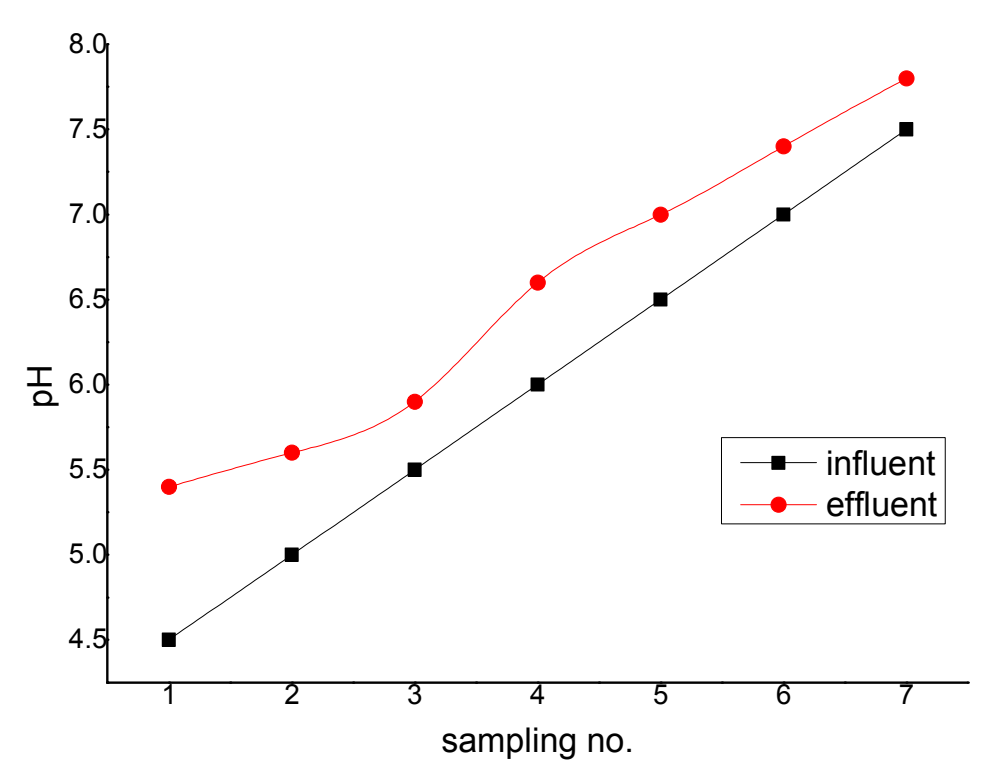

Fig. 4: $\mathrm{pH}$ vs Time

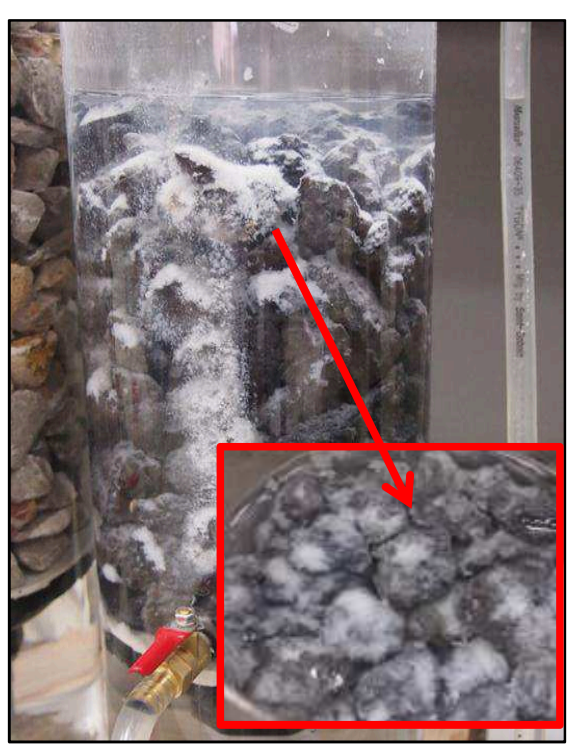

Fig. 5: precipitation in filter

\section{Temperature Profile}

Temperature is also one of the parameters that must be considered in this study of phosphorus removal in wastewater. According to previous study it is clearly stated that the temperature manipulated the mechanism of phosphorus removal. The phosphorus removal range for steel slag was $27-89 \%$ at temperature $27.08^{\circ} \mathrm{C} \pm 0.71$. Fig. 6 shows temperature vs sample date profile.

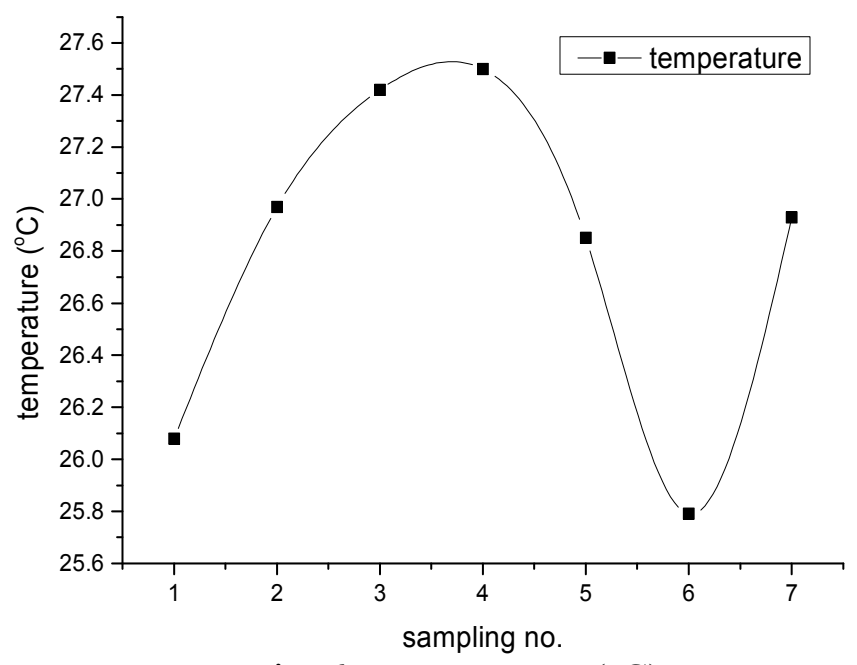

Fig. 6: Temperature $\left({ }^{\circ} \mathrm{C}\right)$

\section{Conclusion}

Results from this study show that steel slag has a high capability in removing phosphorus from synthetic wastewater as almost $90 \%$ of phosphorus has been removed in this experiment. In conclusion, steel slag emerged as one of the promising adsorbent that locally available. In addition, $\mathrm{pH}$ plays an important role in regulating the removal mechanism within the system. As from this 
experiment, it was found that phosphorus from synthetic wastewater was efficiently removed through precipitation at $\mathrm{pH}$ 5.0. Further research will be conducted with in alkaline condition to investigate other mechanism involve at different range of $\mathrm{pH}$.

\section{References}

[1] Vohla, C. et al., (2011). Filter materials for phosphorus removal from wastewater in treatment wetlands-A review. Ecological Engineering, 37(1), pp.70-89.

[2] M.A. Camargo Valero et al., (2009). Enhanced phosphorus removal in a waste stabilization pond system with blast furnace slag filters. Desalination and Water Treatment, 4, pp. 122-127.

[3] Breu, F., Guggenbichler, S. \& Wollmann, J., (2008). A critical look at rock filter. Vasa, 114(1), pp.219-223.

[4] Hamdan, R., (2010). Aerated blast furnace slag filters for enhanced nitrogen and phosphorus removal from small wastewater treatment plants. Ph.D. Thesis. The University of Leeds, School of Civil Engineering.

[5] Bird, S., (2009). Investigations of electric arc furnace slag filters: Phosphorus treatment performance, removal mechanisms and material reuse. MSc. Thesis. The University of Vermont.

[6] Johnson, M., Camargo Valero, M. a. \& Mara, D.D., (2007). Maturation ponds, rock filters and reedbeds in the UK: statistical analysis of winter performance. Water Science \& Technology, 55(11), p.135.

[7] Zhang, H. et al.,(2010). Adsorption Removal of Phosphorus from Aqueous Solution by Steel Slag Columns. $20104^{\text {th }}$ International Conference on Bioinformatics and Biomedical Engineering, pp.1-4.

[8] Li, H. et al., (2012). Phosphorus recovery as struvite from eutropic waters by XDA-7 resin. Water science and technology: a journal of the International Association on Water Pollution Research, 65(12), pp.2091-7.

[9] Erickson, A.J., (2005). Enhanced Sand Filtration for Storm Water Phosphorus Removal. MSc. Thesis. The University of Minnesota. 